\title{
Cyclooxygenase-2 inhibitor, nimesulide, improves radiation treatment against non-small cell lung cancer both in vitro and in vivo
}

\author{
KRISTOPHER R. GRIMES ${ }^{1}$, GRAHAM W. WARREN ${ }^{2}$, \\ FANG FANG ${ }^{3}$, YONG XU ${ }^{3}$ and WILLIAM H. ST. CLAIR ${ }^{1,2}$ \\ ${ }^{1}$ Graduate Center for Nutritional Sciences, ${ }^{2}$ Radiation Medicine, \\ ${ }^{3}$ Graduate Center of Toxicology, University of Kentucky, Lexington, KY, USA
}

Received February 13, 2006; Accepted April 17, 2006

\begin{abstract}
Lung cancer is the leading cause of cancer-related deaths in the United States. Despite improvements in radiation, surgery and chemotherapy the 5 year survival statistics of non-small cell lung cancer (NSCLC) have improved little over the past two decades. It has been proposed that NF- $\mathrm{\kappa B}$ is a participant in the cytoprotection against several redox-mediated therapeutic agents including ionizing radiation. Cyclooxygenase-2 (COX-2) inhibition has become an attractive target for enhancing the efficacy of radiation and chemotherapy. Numerous mechanistic pathways have been proposed as the means through which COX-2 inhibition enhances the efficacy of radiation. We hypothesize that the COX-2 inhibitor, nimesulide, will improve the efficacy of radiation therapy (RT), at least in part, via the suppression of $\mathrm{NF}-\kappa \mathrm{B}$ mediated cytoprotective pathways. In this study we used the COX-2 inhibitor nimesulide to improve the efficacy of RT when measured by tumor regrowth assays in vivo and clonegenic survival in vitro. For the in vivo assay, A549 tumor cells representing NSCLC were subcutaneously injected into the right flanks of female athymic nude mice ( $\mathrm{n}=10 /$ group). Mice were given nimesulide via drinking water at a concentration of $5 \mu \mathrm{g} / \mathrm{g}$ body weight (b.w.) and the water was replenished daily. Tumors were treated with 30 Gy fractionated radiation and measured biweekly. For our in vitro study, clonogenic survival assays were evaluated to determine the effect of nimesulide, radiation, and the combination. The NF- $\mathrm{BB}$ mediated mechanism of nimesulide was measured by Western blot analysis of NF- $\mathrm{KB}$ target genes, MnSOD and survivin. In vivo, mice that received combined treatments of $5 \mu \mathrm{g} / \mathrm{g}$ b.w. nimesulide and $30 \mathrm{~Gy}$ radiation ( $3 \mathrm{~Gy} /$ fraction, 10 daily fractions) had significant reduction in tumor size in comparison to the 30 Gy radiation
\end{abstract}

Correspondence to: Dr William H. St. Clair, University of Kentucky, Department of Radiation Medicine, 800 Rose St., Lexington, KY 40536, USA

E-mail: stclair@uky.edu

Key words: MnSOD, nimesulide, NF-кB control group $(\mathrm{p}<0.05)$. In vitro, nimesulide alone produced a significant decrease in clonogenic survival at doses from 0-300 $\mu \mathrm{M}$. Nimesulide demonstrated an additive effect in combination with radiation. Nimesulide alone reduced MnSOD and survivin protein levels in a dose-dependent manner. 6 Gy radiation caused an initial elevation of MnSOD protein levels which was inhibited by prior treatment of nimesulide suggesting an inhibition of radiation induced NF- $\kappa \mathrm{B}$ target genes. These results support the hypothesis that COX-2 inhibitors such as nimesulide can increase the efficacy of radiation therapy. In vitro, our results suggest that the radiosensitization of A549 tumor cells by nimesulide is mediated by the suppression of $\mathrm{NF}-\kappa \mathrm{B}$-mediated, radiation-induced cytoprotective genes.

\section{Introduction}

The COX family of enzymes plays a primary role in the conversion of arachodonic acid (AA) into a variety of prostaglandins, prostacyclins and thromboxanes through a diverse set of reactions in response to and mediation of cellular inflammatory signals (1-4). There are two main isoforms within the COX family, COX-1 and COX-2, both acting on the same substrate, arachodonic acid, but with distinct regulational expression. COX-1 is generally referred to as a 'house-keeping' protein that is constitutively expressed and is most notably associated with the maintenance of the gastrointestinal mucosa. COX-2 on the other hand is an inducible isoform that is usually expressed at low basal levels until stimulated by many inflammatory mediators such as TNF- $\alpha$ and EGF (5). Recently, COX-2 has become a target for therapeutic intervention in the treatment of cancer, most notably that of colorectal origin $(1,5)$. With mounting evidence that specific inhibitors of COX-2 could prove beneficial in combination with conventional means of cancer treatment, such as radiation, we feel that inhibition of COX-2 may improve the radiosensitization of NSCLC.

Studies, both pre-clinical and clinical, have demonstrated that COX-2 has a critical role in several mechanisms that promote cancer development. Much of the current research is focused on the enzyme's role in angiogenesis, apoptosis, metastasis, cell cycle control and potential transcriptional regulation of certain tumor promoting events. Hong et al 
demonstrated that the selective COX-2 inhibitor nimesulide decreased tumor growth in vivo by overexpression of proapoptotic Bax in relation to anti-apoptotic Bcl-2, thus, promoting cell death (6). Hsu et al showed that celecoxib was able to induce apoptosis by blocking Akt activation in prostate cancer (7). Another strong focus has been placed on NSAID roles in suppression of angiogenesis whereby increasing concentrations of different COX-2 inhibitors have a negative impact on VEGF production while reducing overall tumor growth and proliferation which may have strong implications on metastasis and cell cycle regulation (8-11). It is evident that inhibition of COX-2 could alter many cellular cascades leading eventually to cell death and/or tumor suppression. However, the specific mechanism of how COX-2 inhibition mediates transcriptional regulation is still relatively unclear.

NF- $\mathrm{BB}$ has been shown to be an antagonist to chemoand radiation therapy due to the regulation of specific cytoprotective genes such as sod $2(M n S O D)$, survivin, as well as cox-2. Radiation-induced reactive oxygen species (ROS) production increases redox sensitive $N F-\kappa B$ activity and it has been shown that the NF- $\mathrm{KB}$ pathway will result in cytoprotection of targeted tissues (12-14). By suppressing radiationinduced NF- $\mathrm{KB}$ we hypothesize that tumors will become more vulnerable to radiation insult. It has previously been shown that $\mathrm{NF}-\kappa \mathrm{B}$ can be positively regulated by prostaglandin $\mathrm{E}_{2}$ $\left(\mathrm{PGE}_{2}\right)$, the major product of COX-2-mediated AA metabolism. This activation occurs through $\mathrm{PGE}_{2}$ 's ability to activate the transactivation domain of p65 (15). Interestingly, as previously mentioned, COX-2 is also regulated by NF- $\mathrm{BB}$ through two $\kappa \mathrm{B}$ sites within the promoter region of the gene $(5,15,16)$. Furthermore, it has also been shown that under stress, like radiation, elevated amounts of AA are released from the inner cellular membrane. This correlates with increased COX-2 expression and $\mathrm{PGE}_{2}$ levels $(1,17)$. This information allows for the potential to combine specific COX-2 inhibitors with conformal ionizing radiation to enhance therapeutic efficacy while avoiding typical systemic toxicities accustomed with standard chemotherapy.

We hypothesize that by administering nimesulide, a selective COX-2 inhibitor, both in vitro and in vivo, radiationinduced NF- $\mathrm{\kappa B}$ activity and target cytoprotective proteins will be suppressed. To test this hypothesis, we used an in vivo model to determine the effectiveness of nimesulide in improving the overall efficacy of radiation treatment. In vitro we observed effects of nimesulide and radiation on cell survival and $\mathrm{NF}-\kappa \mathrm{B}$ target protein induction. We conclude that nimesulide improves radiation therapy against NSCLC in part by suppressing radiation-induced NF- $\mathrm{BB}$-targeted cytoprotection.

\section{Materials and methods}

In vivo studies. Six week-old nude mice (NCR nu/nu athymic nude mice), female, weighing 20-24 g (Harlan Labs) were injected with $4 \times 10^{6}$ A549 cells, suspended in $75 \mu 1$ of FBSfree RPMI medium. Injections were subcutaneously placed on the right hind limb of each mouse and tumors were allowed to grow until they reached approximately $250 \mathrm{~mm}^{3}$. Nimesulide treatment was administered orally via drinking water and the water was changed daily for 14 days. Initial studies to test for toxicity and demonstrate effects on tumor growth were performed at a nimesulide concentration of $5 \mu \mathrm{g} / \mathrm{g}$. An additional study was conducted to determine the effects of combining radiation and the inhibitor. In this study, there were two treatment groups ( $30 \mathrm{~Gy}$ and $30 \mathrm{~Gy}+5 \mu \mathrm{g} / \mathrm{g}$ nimesulide) and an untreated control group, each having an $n=10$. Each radiation treatment group received $30 \mathrm{~Gy}$ of X-radiation, $3 \mathrm{~Gy} /$ fraction for 10 consecutive days. Nimesulide was administered one day prior to the first fraction of radiation. Mice were weighed and tumors were measured weekly. Tumors were measured and irradiated according to previous studies (18). Slopes were calculated using the general trend lines of each treatment group. Once tumors reached $\sim 2000 \mathrm{~mm}^{3}$ mice were sacrificed according to a protocol approved by the University of Kentucky IACUC Committee.

Cell culture. The human lung carcinoma cell line, A549 (ATCC), was grown in RPMI media (Sigma, St. Louis, MO, USA) containing 10\% fetal bovine serum (FBS; Sigma), $1 \%$ penicillin/streptomycin, and 1\% L-glutamine (Gibco). Cells were maintained in a $95 \%$ humidified environment at $37^{\circ} \mathrm{C} /$ $5 \% \mathrm{CO}_{2}$ and media was changed every three days. Exponentially growing A549 cells were trypsinized with a $0.05 \%$ trypsin solution and $5 \times 10^{5}$ cells were seeded into $75-\mathrm{cm}^{2}$ filtered flasks. Nimesulide (Sigma) was solublized in DMSO and administered directly to cells with a DMSO concentration not exceeding $1 \%$. In vitro irradiation was performed in a Phillips Industrial X-Ray Irradiator (Yxlon International Inc., Mogadore, $\mathrm{OH}, \mathrm{USA}$ ).

Colony survival assays. A549 cells were split from stock and seeded into $25-\mathrm{cm}^{2}$ flasks at concentrations of 250-8000 cells per flask depending upon the dose of nimesulide and irradiation ( $n=4$ per treatment group). After $24 \mathrm{~h}$, cells were treated with varying doses of nimesulide that ranged from 0-300 $\mu \mathrm{M}$ and doses of radiation that ranged from 0-4 Gy. For groups treated with both nimesulide and radiation, nimesulide was delivered to cells $2 \mathrm{~h}$ prior to radiation. Cells were incubated following all treatments for $24 \mathrm{~h}$ and media was then changed. The undisturbed cells were then allowed to incubate for 15 days at which time they were rinsed with saline, stained and fixed with a methanol/crystal violet solution, and then colonies were counted based on the requirement that a colony must contain at least 50 cells. The surviving fraction for each treatment group was normalized to the surviving fraction of the control (plating efficiency).

Western blot analysis. A549 cells were seeded $1 \times 10^{6}$ in $75-\mathrm{cm}^{2}$ filtered flasks and allowed to grow to $\sim 85 \%$ confluency $(n=3)$. To observe the effects of nimesulide combined with radiation, we treated cells $2 \mathrm{~h}$ prior to radiation with 100 and $300 \mu \mathrm{M}$ nimesulide. We then radiated treated and control groups with a dose of $6 \mathrm{~Gy}$ and allowed the cells to incubate for 22 additional hours at which time cells were harvested. Protein concentrations were analyzed using a standard Bradford protein assay (Bio-Rad Laboratories, Richmond, CA, USA), $30 \mu \mathrm{g}$ of protein was separated on a $12 \%$ SDS-polyacrylamide electrophoresis mini gel at $120 \mathrm{~V}$ for $1 \mathrm{~h}$. Proteins were then transferred to a nitrocellulose membrane (Schleicher \& Schuell, Keene, NH, USA) at $100 \mathrm{~V}$ for $1.5 \mathrm{~h}$. Membranes were probed with anti-MnSOD (Upstate) at a dilution of 1:3000, survivin 


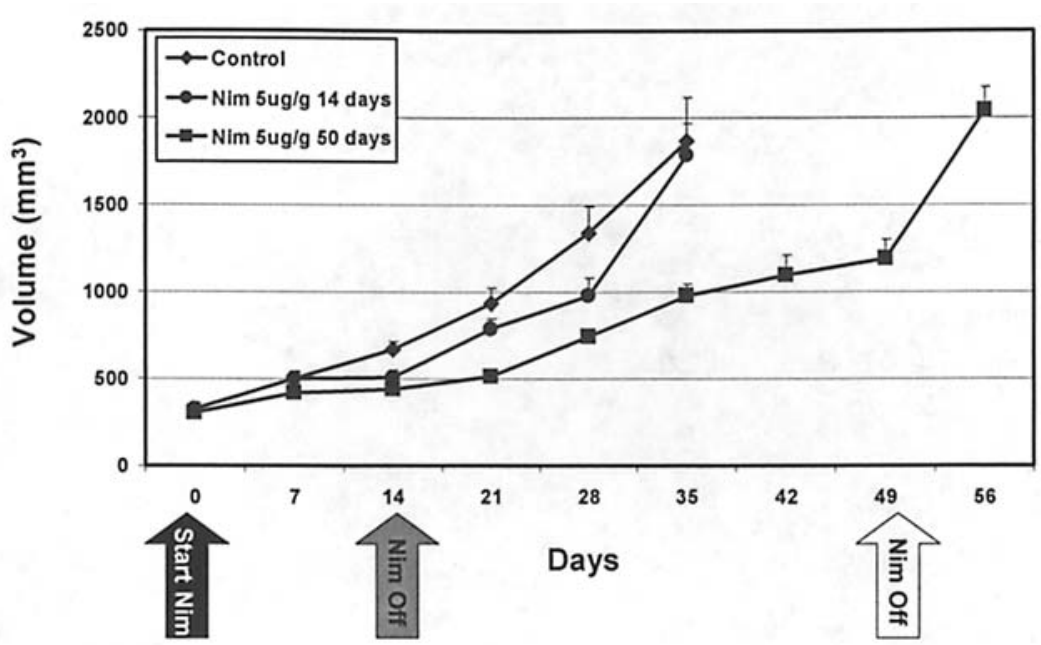

Figure 1. In vivo tumor growth in response to $5 \mu \mathrm{g} / \mathrm{g}$ nimesulide for 14 and 50 days. Mice that were treated with nimesulide for 14 days demonstrated a slight delay in tumor growth as compared to control. However, tumor growth was substantially delayed when mice were treated for 50 days ( $\mathrm{p}<0.05$ ).

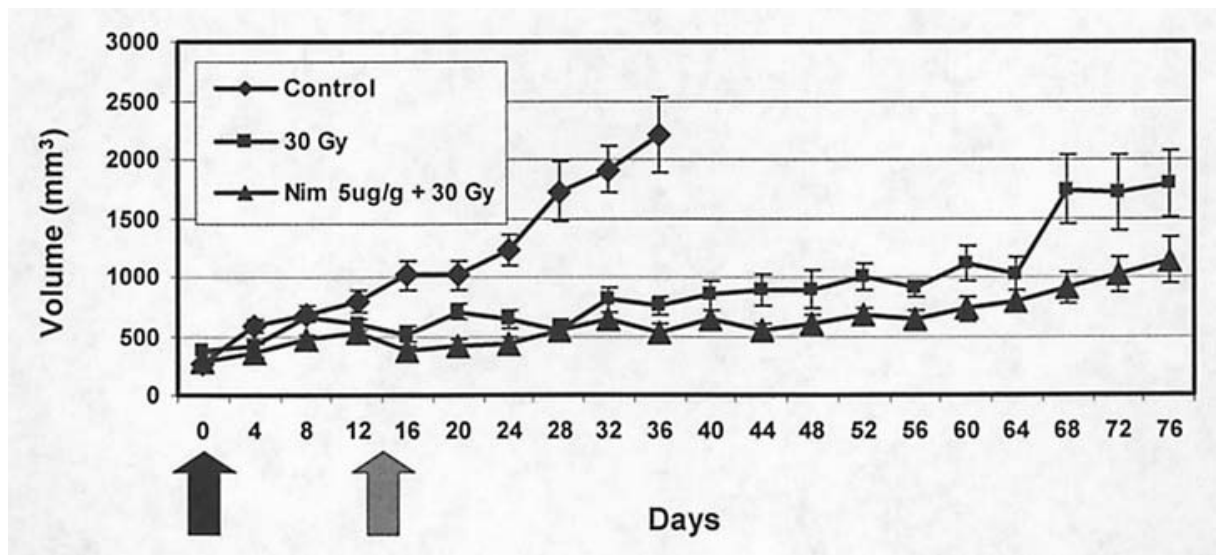

Figure 2. In vivo tumor growth response to $5 \mu \mathrm{g} / \mathrm{g}$ nimesulide with/without $30 \mathrm{~Gy}$ fractionated radiation. Mice that received nimesulide in combination with radiation demonstrated a significant overall delay in tumor growth in comparison to untreated tumors or those treated with radiation alone ( $<<0.05$ ). Arrows indicate the beginning and end of nimesulide treatment.

(Novus) at a dilution of 1:2000, and then stripped for $45 \mathrm{~min}$ at $55^{\circ} \mathrm{C}$ and normalized to anti- $\beta$-actin (Sigma) with a dilution of 1:2000. Measurement and detection of proteins were determined as previously demonstrated $(18,19)$.

Statistical analysis. Statistical analysis of in vitro studies was performed by one-way ANOVA and Newman-Keuls post test. Nimesulide and radiation interaction was determined by two-way ANOVA and a Bonferroni post test. Tumor sizes were analyzed by using protected LSD to test for differences.

\section{Results}

Nimesulide improves radiation efficacy in vivo. Preliminary investigations demonstrated that nimesulide administered continuously for 14 days initially delayed tumor growth. However, once treatment ended, tumors resumed rapid unabated growth and eventually reached the maximum allowable size, $2000 \mathrm{~mm}^{3}$, at the same time as the untreated group (Fig. 1). Mice treated with the same dose of nimesulide continuously for 50 days demonstrated a significant delay in tumor growth
(Fig. 1) without indication of overt toxicity based upon body weights. However, once treatment ended, tumor growth significantly increased and tumors reached their maximum allowable volume one week following the end of treatment. When combined with 30 Gy fractionated radiation, groups that were treated with nimesulide for 14 days exhibited a significant increase in tumor growth delay as compared to radiation alone $[\mathrm{p}<0.05$ (Fig. 2)]. Consistent with these findings, it took nearly 15 days longer for tumors treated with nimesulide and radiation to reach $50 \%$ of the allowable tumor size in comparison to the radiation control group and the slope of the growth trend was nearly $46 \%$ less than the same group (Table I).

Clonogenic survival demonstrates improved radiation sensitivity in vitro. The radiation sensitivity of A549 cells was evaluated in the absence or presence of increasing concentrations of nimesulide. Cells were exposed to graded doses of X-radiation (0-4 Gy) and/or increasing doses of nimesulide $(0-300 \mu \mathrm{M})$ and allowed to form colonies. Fig. 3 displays the surviving fraction of A549 cells treated with radiation alone, 
Table I. Number of days for tumors within a treatment group to reach $1000 \mathrm{~mm}^{3}$ (50\% of the allowable tumor size) and slope of each respect growth trend.

\begin{tabular}{lcc}
\hline Treatment & Days & Slope \\
\hline $\begin{array}{l}\text { Control } \\
\text { (Untreated) }\end{array}$ & 15.80 & 201.32 \\
$30 \mathrm{~Gy}$ & 57.80 & \\
$\begin{array}{l}\mathrm{X} \text {-radiation } \\
\text { Nimesulide }\end{array}$ & & 62.943 \\
$5 \mu \mathrm{g} / \mathrm{g}+30 \mathrm{~Gy}$ & 72.20 & 34.064 \\
\hline
\end{tabular}

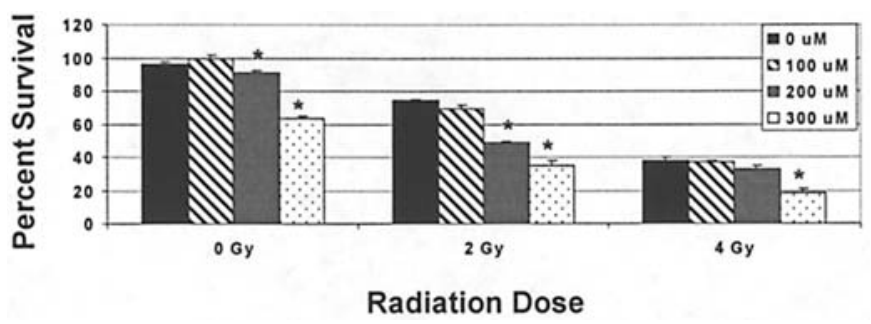

Figure 3. Clonegenic survival assay demonstrating radiosensitizing effects of nimesulide in a dose-dependent fashion. Nimesulide significantly sensitized A549 cells to radiation between the dose range of 0 and 4 Gy. Nimesulide was given $2 \mathrm{~h}$ prior to radiation treatment and the medium was changed $24 \mathrm{~h}$ later. Two-way ANOVA demonstrated a significant interaction between radiation and nimesulide $(\mathrm{p}<0.0001)$.

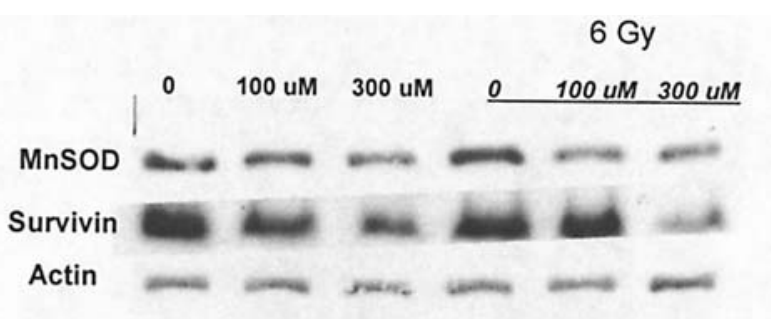

Figure 4. Nimesulide suppresses survivin and radiation-induced MnSOD protein levels at $24 \mathrm{~h}$. Nimesulide successfully reduces survivin and MnSOD protein levels following $24 \mathrm{~h}$ treatment. A 2-h pretreatment of nimesulide inhibits radiation-induced MnSOD levels confirming inhibition of $\mathrm{NF}-\kappa \mathrm{B}$ activity.

nimesulide or the combination. The results demonstrate that increasing doses of both radiation and nimesulide caused increased cell killing. Two-way ANOVA reveals a significant interaction between radiation and nimesulide with respect to surviving fraction $(\mathrm{p}<0.001)$.

Nimesulide suppresses MnSOD and survivin protein levels before and after 6 Gy radiation treatment. After confirming that nimesulide was effective at improving the radiation sensitivity of A549 cells, we performed Western analysis of MnSOD and survivin proteins.

We evaluated the levels of $N F-\kappa B$ target protein $24 \mathrm{~h}$ following $6 \mathrm{~Gy} \mathrm{X}$-radiation with and without pretreatment of either 100 or $300 \mu \mathrm{M}$ nimesulide. 6 Gy irradiation initially increased MnSOD protein levels but when nimesulide was combined with 6 Gy X-radiation, the radiation induction of MnSOD was suppressed. Nimesulide suppressed survivin levels in a dose-dependent fashion prior to and in combination with radiation treatment. These results suggest that nimesulide suppresses the pro-survival proteins MnSOD and survivin via the inhibition of the NF-кB (Fig. 4).

\section{Discussion}

In recent years there has been a great amount of emphasis placed on the investigation of COX-2 inhibitors as potent anticancer agents, specifically in correlation with colon cancer. However, in recent months we have seen the negative implication of certain COX-2 inhibitors as being related to the increase in risk of cardiotoxicity (20-22). While these findings are problematic for long-term use, the possibilities of using COX-2 inhibitors for a short term in combination with ionizing radiation therapy are intriguing. Several studies have shown that COX-2 inhibitors reduce the growth of tumors in vivo and in vitro and can enhance the radiosensitivity of certain tumors (23-29). While there has been a great deal of research and speculation on the exact mechanism by which COX-2 inhibitors produce their anti-tumor effect, there has been no definitive answer to explain the phenomenon or how COX-2 inhibitors enhance the effects of radiation therapy.

$\mathrm{NF}-\kappa \mathrm{B}$ is an important transcription factor in cytoprotection against several diverse forms of redox-related stresses including radiation. Following radiation treatment, increased activity of $\mathrm{NF}-\kappa \mathrm{B}$ induces cytoprotective genes such as $\operatorname{sod} 2$ (MnSOD). MnSOD is a primary antioxidant responsible for scavenging superoxide in the mitochondria. It has been shown in previous studies that radiation-induced MnSOD protein leads to enhanced radiation resistance (18,31-33). It has also been shown that $\mathrm{PGE}_{2}$, a major product of arachodonic metabolism, can activate NF- $\mathrm{KB}$ via the transactivation domain of Rel A (15). Upon radiation insult, an influx of arachodonic acid from the membrane is released into the cytosol for metabolism during the cell's inflammation response. This further promotes the concept that NF-кB can be induced during radiation treatment as well as other inducers of oxidative stress including inflammation. In this study, we demonstrate that nimesulide will improve the efficacy of fractionated radiation therapy against non-small cell lung cancer, in part, by suppressing radiation induced NF- $\mathrm{\kappa B}$ activation and subsequent MnSOD and survivin protein levels.

In vitro, we demonstrate that nimesulide can improve radiation therapy against NSCLC using a clonogenic survival assay. This effect is most readily observed at lower doses of radiation, between 0-4 Gy of IR. This is a significant finding suggesting that, at doses relevant to clinical fractionated radiation, nimesulide may prove to enhance tumor radiosensitization. In addition to this, we also observed the effects of nimesulide alone and in combination with radiation on the $\mathrm{NF}-\kappa \mathrm{B}$ target gene products MnSOD and survivin. We found that at $24 \mathrm{~h}$ there was a dose-dependent decrease of MnSOD and survivin levels at nimesulide concentrations of 100-300 $\mu \mathrm{M}$ while nimesulide also suppressed the inducible levels of MnSOD following radiation. 
In addition to the in vitro assays that helped us determine the mechanism of nimesulide action, the effect of the inhibitor in an in vivo model via a tumor regrowth assay was tested to access the potential of short-term nimesulide use to improve the radiation effect against tumor growth. Initial studies revealed that administering nimesulide through drinking water had little to no effect on tumor growth when given for a 14-day period without radiation. However, when nimesulide at a concentration of $5 \mu \mathrm{g} / \mathrm{g}$ b.w. was delivered in combination with 30 Gy fractionated radiation, we found a significant reduction in tumor growth in comparison to nimesulide and radiation control groups. It is important to note that when nimesulide was delivered, with or without radiation, there was no reduction in body weight, indicating the absence of overt toxicity.

Previously mentioned studies have shown that COX-2 inhibitors delivered to animals without radiation can slow tumor growth. This was not clearly demonstrated in our model where nimesulide was administered for the shortest time frame. However, groups treated with $5 \mu \mathrm{g} / \mathrm{g}$ nimesulide for 50 days, as compared to those treated for 14 days, demonstrated impaired tumor growth without overt toxicity. This information suggests that while nimesulide, when given alone, may have a more significant effect during prolonged administration, when coupled with radiation, short-term use of nimesulide improves overall radiation sensitivity without overt toxicity.

In summary, our results suggest that there is a pertinent role for COX-2 inhibitors, such as nimesulide, in a dual modality therapy approach with radiation for the treatment of non-small cell lung cancer. We have demonstrated that nimesulide can improve the efficacy of fractionated X-radiation by suppressing the redox sensitive NF- $\mathrm{KB}$ leading to the reduction of cytoprotective proteins such as MnSOD and survivin. Future studies should investigate dosing at different time intervals as well as the non-specific interactions of COX-2 inhibitors which may lead to altered tumor growth patterns. Overall, it seems that there is good evidence that nimesulide and related COX-2 inhibitors can be used in short-term conditions in combination with radiation to improve cancer control.

\section{Acknowledgements}

This study was supported by Kentucky Lung Cancer Research Program and NIH Grant T32 DK07778.

\section{References}

1. Church R, Fleshman J and McLeod H: Cyclo-oxygenase 2 inhibition in colorectal cancer therapy. Br J Surg 90: 1055-1067, 2003.

2. Hawkey C: COX-1 and COX-2. Best Pract Res Clin Gast 15: 801-820, 2001

3. Simmons D, Botting R and Hla T: Cyclooxygenase isozymes: the biology of prostaglandin synthesis and inhibition. Pharmacol Rev 56: 387-437, 2004.

4. Vane J, Bakhle Y and Botting R: Cyclooxygenases 1 and 2. Annu Rev Pharmacol Toxicol 38: 97-120, 1998.

5. Ricchi P, Zarrilli R, Palma A and Acquaviva A: Non-steroidal anti-inflammatory drugs in colorectal cancer: from prevention to therapy. Br J Cancer 88: 803-807, 2003.

6. Li X, Li J, Zhang H, Sun P, Zhang Y, Cai S and Ren X: Nimesulide inhibits tumor growth in mice implanted hepatoma: overexpression of Bax over Bcl-2. Acta Pharmacol Sinica 24: 1045-1050, 2003.
7. Hsu A, Ching T, Wang D, Xueqin S, Rangnekar V and Chen C: The cyclooxygenase-2 inhibitor celecoxib induces apoptosis by blocking Akt activation in human prostate cancer cells independently of Bcl-2. J Biol Chem 275: 11397-11403, 2000

8. Dormond $\mathrm{O}$ and Ruegg C: Inhibition of tumor angiogenesis by non-steroidal anti-inflammatory drugs: emerging mechanisms and therapeutic perspectives. Drug Res Updates 4: 314-321, 2001.

9. Choy $\mathrm{H}$ and Milas L: Enhancing radiotherapy with cyclooxygenase-2 enzyme inhibitors: a rational advance? J Natl Cancer Inst 95: 1440-1452, 2003.

10. Iniquez M, Rodriguez A, Volpert $\mathrm{O}$, Fresno $\mathrm{M}$ and Redondo J: Cyclooxygenase-2: a therapeutic target in angiogenesis. Trends Mol Med 9: 73-78, 2003.

11. Shin Y, Park J, Kim H, Jun H, Kim G, Suh C, Yun Y and Pyo H: Radiosensitivity enhancement by celecoxib, a cyclooxygenase (COX)-2 selective inhibitor, via COX-2-dependent cell cycle regulation on human cancer cells expressing differential COX-2 levels. Cancer Res 65: 9501-9509, 2005

12. Brach M, Hass R, Sherman M, Gunji H, Weichselbaum R and Kufe D: Ionizing radiation induces expression and binding activity of nuclear factor $\mathrm{\kappa B}$. J Clin Invest 88: 691-695, 1991.

13. Pajonk F, Pajonk K and McBride W: Apoptosis and radiosensitization of hodgkin cells by proteasome inhibition. Int $\mathrm{J}$ Radiat Oncol Biol Phys 47: 1025-1032, 2000.

14. Egan L, Eckmann L, Greten F, Chae S, Li Z, Myhre G, Robine S, Karin $M$ and Kagnoff M: IкB-kinaseß-dependent NF-кB activation provides radioprotection to the intestinal epithelium. Proc Natl Acad Sci USA 1001: 2452-2457, 2004.

15. Poligone $\mathrm{B}$ and Baldwin A: Positive and negative regulation of NF-кB by COX-2. J Biol Chem 276: 38658-38664, 2001.

16. Chun K and Surh Y: Signal transduction pathways regulating cyclooxygenase-2 expression: potential molecular targets for chemoprevention. Biochem Pharmacol 68: 1089-1100, 2004.

17. Pilane $\mathrm{C}$ and Labelle E: Arachidonic acid release by $\mathrm{cPLA}_{2}$ may be causally related to NO-induced apoptosis in vascular smooth muscle cells. J Cell Physiol 191: 191-197, 2002.

18. Grimes K, Daosukho C, Zhao Y, Meigooni A and St. Clair W: Proteasome inhibition improves fractionated radiation treatment against non-small cell lung cancer: an antioxidant connection. Int J Oncol 27: 1047-1052, 2005.

19. Zhao Y, Kiningham K, Lin S and St. Clair D: Overexpression of MnSOD protects murine fibrosarcoma cells (FSa-II) from apoptosis and promotes a differentiation program upon treatment with 5-azacytidene: involvement of MAPK and NF-кB pathways. Antioxidants Redox Signal 3: 375-385, 2001.

20. Davies $\mathrm{N}$ and Jamali F: COX-2 selective inhibitors cardiac toxicity: getting to the heart of the matter. J Pharm Pharmaceut Sci 7: 332-336, 2004.

21. Justice E and Carruthers D: Cardiovascular risk and COX-2 inhibition in rheumatological practice. J Hum Hypertens 19: 1-5, 2005.

22. Krotz F, Schiele T, Klauss V and Sohn H: Selective COX-2 inhibitors and risk of myocardial infarction. J Vasc Res 42: 312-324, 2005.

23. Hida T, Kozaki K, Muramatsu H, Mauda A, Shimizu S, Mitsudomi T, Sugiura T, Ogawa M and Takahashi T: Cyclooxygenase- 2 inhibitor induces apoptosis and enhances cytotoxicity of various anticancer agents in non-small lung cancer cell lines. Clin Cancer Res 6: 2001-2006, 2000.

24. Pyo H, Choy H, Amorino G, Kim J, Cao Q, Hercules S and DuBois R: A selective cyclooxygenase-2 inhibitor, NS-398, enhances the effect of radiation in vitro and in vivo preferentially on cells that express cyclooxygenase-2. Clin Cancer Res 7: 2998-3005, 2001.

25. Raju U, Nakata E, Yang P, Newman R, Ang K and Milas L: In vitro enhancement of tumor cell radiosensitivity by a selective inhibitor of cyclooxygenase-2 enzyme: mechanistic considerations. Int J Radiat Oncol Biol Phys 54: 886-894, 2002.

26. Yamazaki R, Kusunoki N, Matsuzaki T, Hashimoto S and Kawai S: Selective cyclooxygenase-2 inhibitors show a differential ability to inhibit proliferation and induce apoptosis of colon adenocarcinoma cells. FEBS Lett 531: 278-284, 2002.

27. Kim H, Youm H, Lee J, Min K, Chung J and Park C: Correlation between cyclooxygenase- 2 and tumor angiogenesis in non-small cell lung cancer. Lung Cancer 42: 163-170, 2003.

28. Wen B, Deutsch E, Eschwege P, Crevoisier R, Nasr E, Eschwege F and Bouris J: Cyclooxygenase-2 inhibitor NS398 enhances antitumor effect of irradiation on hormone refractory human prostate carcinoma cells. J Urol 170: 2036-2039, 2003. 
29. Shaik M, Chatterjee A and Singh M: Effect of a selective cyclooxygenase- 2 inhibitor, nimesulide, on the growth of lung tumors and their expression of cyclooxygenase- 2 and peroxisome proliferators-activated receptor- $\gamma$. Clin Cancer Res 10: 1521-1529, 2004.

30. Eastgate J, Moreb J, Nick H, Suzuki K, Taniguchi N and Zucali J: A role for manganese superoxide dismutase in radioprotection of hematopoietic stem cells by interleukin-1. Blood 81: 639-646, 1993.
31. Wong G: Protective roles of cytokines against radiation: induction of mitochondrial MnSOD. Biochim Biophys Acta 127: 205-209, 1995

32. Epperly M, Bray J, Kraeger S, et al: Prevention of late effects of irradiaton lung damage by manganese superoxide dismutase gene therapy. Gene Ther 5: 196-208, 1998.

33. Josson S, Xu Y, Fang F, Dhar S, St. Clair D and St. Clair W: RelB regulates manganese superoxide dismutase gene and resistance to ionizing radiation of prostate cancer cells. Oncogene 25: $1554-1559,2006$. 